\title{
Cohesion and Coherence in Final Project Abstracts Written by Non- English Department Undergraduate Students
}

\author{
Nindya Septarica Happy Gusnar ${ }^{1 凶}$, Rudi Hartono ${ }^{2}$, Suwandi Suwandi ${ }^{3}$ \\ 1. CLT Unika Semarang, Indonesia \\ 2. Universitas Negeri Semarang, Indonesia \\ 3. Universitas PGRI Semarang, Indonesia
}

\begin{abstract}
Article Info
Article History:

Recived 28 July 2021

Accepted 3 October

2021

Published 23

December 2021

\section{Keywords:}

abstract, cohesion, coherence, written discourse analysis

Abstract

Creating text needs to be understood that it is not only about arranging the words into sentences and paragraphs but also delivering meaning. Unfortunately, not everyone can achieve good skills in writing. This study aims at analyzing the writing skills of a group of Indonesian non-English department undergraduate students. It focused on the cohesion and coherence of their production of the final project abstract. Ten texts were analyzed by employing a discourse analytical case study. Thus, it is an important matter to analyze the writing competency of students as they are at the undergraduate level, majoring in Informatics Engineering that should report their final project in English. In this study, a theory from Halliday and Matthiessen (2014) was used to analyze the cohesion while a theory from Eggins (2004), Thornburry (2005), and Paltridge and Starfield (2007) were used to analyze the coherence. An open-ended questionnaire was used to confirm the result of the analysis according to the writers' point of view. The findings indicate that the students show a bit of weakness in achieving cohesion and coherence in creating texts due to a lack of knowledge about the theory of cohesion and coherence. The result of the study can be used as a reference and consideration in designing a suitable lesson plan for writing class.
\end{abstract}




\section{INTRODUCTION}

Language becomes a crucial role of social life since it acts as a tool to express people's thoughts, feelings, and ideas. As a part of the global community, English is considered as an international language to ease communication among people across the world (Weigle, 2011). Communication can be implemented through text. Text is a meaningful unit that is coherent and appropriate in its context (Hartono \& Purwanto, 2017). In creating text, it is not only about arranging the words into sentences and paragraphs but also delivering meaning through words. Good construction of text consists of some elements that are inseparable and meaningful known as cohesion and coherence (Thornbury, 2005). Cohesion comprises grammatical and lexical cohesion. It functions to connect the words at the semantic level. Furthermore, the text also needs to be accepted by readers' expectations known as coherence. It eases readers to identify a certain genre of text to meet extra-textual context. These two elements are the focus of this present study. Unfortunately, not everyone can achieve good skills in writing sinceit is considered as the most difficult skill for English as a Foreign Language (EFL) learner (Kilic et al., 2016). This might happen because a foreign language consists of complex elements such as grammar, vocabulary, and rhetorical conventions (Suwandi, 2015).

Some studies related to cohesion and coherence text analysis have been carried out, especially in English language teaching. Fitriati and Yonata (2017) investigated the text analysis of coherence in graduate students of English argumentative writing. Employing a discourse analytical case study, the findings reveal that the students still have difficulties in achieving coherency because they do not maximize the use of cohesive devices especially conjunctions to relate the sentences. Furthermore, Suwandi (2015) analyzed cohesion and coherence in undergraduate English language department students' final project abstracts. The result of this study reveals that the students used cohesive devices to achieve coherency even though it is still far from the readers' expectations.

Inspired by these previous studies, this study concerns to the learners' ability in creating good text. This is important issues to discuss how students use elements of cohesion and coherence to affect their writing quality (Karadeniz, 2017). Students of the undergraduate program in this present study are Informatics Engineering students that work with the technology program. Therefore, as IT programmers, they are expected to be able to write good texts to provide clear information from their research or IT development.

The students' texts examined are final project abstracts. This kind of text inquires the writers to report the result of their research in a brief explanation in order to ease the reader discerns what the research is in short period.

The present study is aimed to reveal the text cohesion and coherence of the final project abstract written by Informatic Engineering undergraduate students at Soegijapranata Catholic University. The major cause of choosing this level of students is that, as they are at the university level, they are assumed to have good writing skills. In addition, they have got English lessons as the general lecture. This analysis is needed to acknowledge the present condition of their ability in conveying their ideas through the text. As Informatics Engineering undergraduate students, they need to be able to express their ideas coherently in the written form of the final project as the requirement for their graduation. Moreover, whenever they conduct research in terms of IT development, they can share the result with people around the world using English as media to communicate.

In conducting research, there should be a novelty. In this case, the current study involvedInformatics Engineering undergraduate students as the subjects of the study. As far as it is concerned, little is known about the writing ability of non-English department students as EFL learners in terms of their skills in making a cohesive and coherent text.

This study used the theory proposed by Halliday and Matthiessen (2014) to examine 
cohesion. The cohesiveness of a text may be examined through grammatical cohesion and lexical cohesion. In terms of grammatical cohesion, four categories can be analyzed. Those are reference, substitution, ellipsis, and conjunction. Further, lexical cohesion offers the variety in choosing words by using repetition, synonymy, hyponymy, meronymy, and collocation. While coherence was analyzed through the theory proposed by Eggins (2004) and Thornbury (2005). In terms of coherence, two points of view should be examined. First is micro-level coherence, it is reached if the text answers the readers' expectation through themerheme pattern and logical relation among the sentences. The second is the macro level of coherence. It is achieved through the detected topic and certain genres of the text.

The objectives of this study can be formulated as follows: (1) To analyze what kind of cohesion is used in the final project abstract, (2) To explain the quality of cohesion in the final project abstract, (3) To analyze the quality microlevel coherence in final project abstract, (4) To observe macro-level coherence in final project abstract, (5) To reveal why the students used these kinds of cohesion and coherence in the final project abstract, (6) To give suggestion how to write good final project abstract with correct cohesion and coherence.

\section{METHODS}

This research employs qualitative case study probing answers such as what, how, and why Indonesian non-English department undergraduate students in achieving cohesion and coherence in their final project abstracts, employing written discourse analysis. This study analyzed written text naturally since the writers of the texts were not told that their writings would be used as the object of the research in the beginning.

The source of the data was taken from the university's repository. There were ten final project abstracts written by non-English department undergraduate students at a private university in a city in the Central Java Province,
Indonesia. Because this is a case study, the researcher took ten texts purposively. After choosing the texts, the researchers asked permission from the ten students to use their texts as the object of this study. Due to its limitation, the findings of this study can not be generalized. But it is hoped that the current study can be used as consideration for further research dealing with cohesion and coherence.

The data examination was started by analyzing clauses. Furthermore, each clause was analyzed in terms of cohesive devices. The findings of the cohesive devices were presented in tables which then were elaborated. Then it is continued by analyzing the text coherence. The text was analyzed in terms of micro-level and macro-level coherence. In terms of the microlevel coherence, the texts were examined through thematic patterns and logical relationships across the sentences. Further, in terms of the macro-level coherence, the analysis was done in examining the topic and generic structure. An open-ended questionnaire was used to confirm the data analysis from the writers. The data examination required complex process analysis by the researchers following the theoretical framework of cohesion and coherence proposed by Halliday and Matthiessen (2014), Eggins (2004), Thornburry (2005), and Paltridge and Starfield (2007).

\section{RESULTS AND DISCUSSIONS}

This part discussesthe findings and discussions on cohesive devices in each text and is followed by the findings and discussions on the text coherence with regard to micro- and macrolevel coherence analysis. Further, the writers' point of view will support the result of data analysis and there will be explanation on how to write good final project abstract proposed by the experts.

\section{Cohesion \\ Grammatical cohesion}

This discussion section is started by answering the first and second research questions related to cohesive devices used and their quality 
in the final project abstract. The first type of cohesion device is grammatical cohesion. It consists of reference, substitution, ellipsis, and conjunction (Halliday \& Matthiessen, 2014). The first existence of grammatical cohesion is a reference where it involves three different classifications. The first is an exophoric reference. The retrieval is drawn from the shared immediate context of a situation. The second is an endophoric reference. The identity of a referent item is taken from within a text that involved anaphoric and cataphoric references. The anaphoric reference appears when the referent has occurred in the previous part of the text while the cataphoric reference appears when the referent will be provided in the following sentence in the text. The third is homophoric reference. It occurs if the retrieval is taken from the shared context of culture (Eggins, 2004).

Based on the analysis, it is found that a great number of references was used in the texts. The number of references found in text 1 is eleven anaphoric, one cataphoric, and four exophoric. Text 2 has eight anaphoric and seven exophoric. Text 3 has six anaphoric and six exophoric. Text 4 has sixteen anaphoric and three exophoric. Text 5 has five anaphoric, three exophoric, and one cataphoric. Text 6 has fifteen anaphoric, twelve exophoric, and one cataphoric. Text 7 has seven anaphoric, two cataphoric, and seven exophoric. Text 8 has fourteen anaphoric, nine exophoric, and three cataphoric. Text 9 has seventeen anaphoric, four exophoric, and four cataphoric. Text 10 has two anaphoric, six exophoric, and three cataphoric. Article the and demonstrative this in the sentence below is proving the presence of reference. The problem in this project is about inventory. It can be seen that the writer tried to make cohesive text by using demonstrativereference The problem contains cataphoric reference because the refers to the problem faced by the investor that explained in the following sentence For exporters, it is certainly very difficult to know the inventory of goods that must be prepared every month. Moreover, this project contains exophoric references because "this" refers to a project study that has been conducted by the writer.
The analysis showed that the existence of endhophora and exophora reference indicates that the writer succeeded in using reference in their text. Homophoric reference was not found in this research since the readers already know that this text is in the form of final project abstract that deals with research. Reference is often used by writers. These findings confirm some studies from Malah (2015); Priangan et. al. (2019); Ampa and Basri (2019) that reference is the type of grammatical cohesion frequently used in writing text by the writers.

The second part is to find substitution of clause elements wether it is clausal, verbal or nominal. One evidence is found in the first text. One in the following sentence indicate the use of nominal substitution since one subtitutes the word exporters. If one provides goods inventory, it will hamper the sale of goods. Another part is to find ellipsis wether it is clausal, verbal or nominal. One evidence is found in fifth text. It can be seen in following sentence that the word water was ommitted in adjective clause. Water become one of the elements that can meet our daily needs and guarantee the continuity of life.

Regarding to the presence of substitution and ellipsis, there was only one for each of them. Both of them are in the form of nominal. These two kinds of grammatical devices were rarely used by the writer of the text. This finding corroborates Alzankawi's study (2017) that the EFL students neglecting to use substitution and ellipsis in writing text. Ellipsis and substitution are used more in speech than in writing (Tajeddin \& Rahimi, 2017).

Further, another part related to grammatical cohesion is conjunction. Text 1 employs if and so that as enhancement: causalconditional - general; in addition and and as extension: addition-positive. Text 2 employs conjunction and as extension: addition-positive; but as extension: addition-adversative; and then as enhancement: spatio-temporal; temporal -simple - following. Text 3 employs conjunction and as extension: addition-positive; for the example as elaboration: apposition - exemplifying; for as enhancement: causal-conditional - general. Text 4 employs conjunction actually as elaboration: 
clarification - verificative; and as extension: addition-positive; because and if as enhancement: causal-conditional - general. Text 5 employs conjunction and as extension: addition-positive; therefore as enhancement: causal-conditional general. Text 6 employs conjunction because, therefore, so that as enhancement: causalconditional - general; and as extension: additionpositive. Text 7 employs conjunction and as extension: addition-positive; so that and because as enhancement: causal-conditional - general. Text 8 employs con junction for as enhancement: causal-conditional - general; but as extension: addition-adversative; andas extension: additionpositive. Text 9 employs conjunction as if and because of that as enhancement: causalconditional-general; and as extension: additionpositive; However as extension: additionadversative. Text 10 employs conjunction and as extension: addition-positive; if as enhancement: causal-conditional-general.

Discussing conjunctions used in the text, the result showed that there was the existence of three types of conjunction. It indicates that the writer was successful enough in achieving coherency of the text by employing conjunction. Moreover, This finding corroboratesNugraheni (2015) and Nilopa et al., (2017) study that the most frequent type of conjunction used by the writer is a conjunction and as an extension: addition-positive.

Furthermore, there are ]kinds of conjunctions proposed by Halliday and Matthiessen (2014) used by the writer to achieve coherency using grammatical devices.

The result of grammatical cohesion analysis seems less optimized due to its limitation in the use of ellipsis and substitution. The earlier studies also acknowledge that these two elements are rarely used by the writers in creating a text (Sadighi \& Heydari, 2012; Suwandi, 2015; Afrianto, 2017). While reference and conjunction are type of grammatical cohesion commonly used by the writers because the students are familiar with these types (Adiantika, 2015; Alzankawi, 2017). Four types of grammatical cohesion should be used bythe writer in the average portion of occurrence in the text.

\section{Lexical cohesion}

Lexical cohesion is achieved through the choice of lexical items. It is realized in terms of word repetition or repeating lexical item in the text, synonymy that words have similar meaning, hyponymy is particular member of words that belongs to broader class, meronymy is word that is part of something and collocation is word tendency to co-occur following some word (Halliday \& Matthiessen, 2014).

Based on the analysis, Text 1 has repetition of word inventory $(7 \mathrm{x})$ and synonymy word good with item (7x). Text 2 has repetition of word sensor $(2 \mathrm{x})$, data $(4 \mathrm{x})$, power $(2 \mathrm{x})$ and hyponymy of word application-telemedicine and study - research. Text 3 has repetition of word investment (1x), product $(3 \mathrm{x})$, investor $(2 \mathrm{x})$, data $(2 \mathrm{x})$, project $(3 \mathrm{x})$. Text 4 has repetition of the word security (2x), synonymy login section and login site; user and someone, hyponymy technology and system. Text 5 has repetition of word water (4x). Text 6 has repetition of word scientific journal (7x) and synonymy study and research. Text 7 has repetition of word scheduling $(2 \mathrm{x})$, organization $(2 \mathrm{x})$, churchservant (2x); synonymy the word study and project; meronymy the word organization - division member. Text 8 has repetition of word insurance company $(2 \mathrm{x})$, insurance program $(2 \mathrm{x})$, claim $(2 \mathrm{x})$, synonymy of the word people - someone-human, research and project. Text 9 has repetition of word student (2x). Synonymy lamp and light. Meronymy temperature and cold. Text 10 has synonymy detection and recognition; meronymy body - face - eyes - mouth. Unfortunately, there was no lexical variation in terms of using collocation.

There should be five types of lexical cohesion in the students' text. In fact, there are only four types of lexical cohesion employed by the writer in writing the text. Those were repetition, synonymy, hyponymy, and meronymy. Repetition is the most type of lexical cohesion used by the writer. This finding verifies Bahaziq's study (2016) that non-native students tend to use repetition due to their limitation of vocabulary mastery. It functions to let readers pay more attention to the things central to the discussion. In terms of synonymy, the writers of the text were able to use synonymy to avoid the 
monotonous text using the same word. The occurrence of synonymy is quite a lot as the students can use synonymous words/phrases when needed (Masadeh, 2019). Hyponymy is another type of lexical cohesion used by the writers. It connects the word as its meaning relationship of one word with others. Even though the occurrence was limited, it proved that the writers were able to apply this type of lexical cohesion to their texts. Meronymy was also found in the text. It tied the word from its relation as the part of something. The occurrence of meronymy was also limited. These two types of lexical cohesion is rarely used by the writers in creating text (Heni et al., 2018). While collocation was not found in the text. This finding corroborates Priangan et al. (2019) study that not all types of lexical cohesion are found in the students writing. There is no collocation found in the text.From these findings, it may describe that the writers produce limited lexical variations in the texts. The discussion reveals that the writer used two types of cohesion. Even though, some of them were in limited occurrence or none.

\section{Coherence}

Coherence analysis involved two aspects known as micro- and macro-level coherence. Micro-level coherence covers on the analysis of thematic progression with its logical relations within the text. It focuses on the development of theme and rheme in the clause (Shakeh, 2016). In terms of thematic pattern, as Eggins (2004) argues there are three main patterns of thematic development can be observed namely theme reiteration, zig-zag pattern, and multiple-rheme pattern.Theme reiteration functions in keeping a text-focused by having the same theme or referent in the whole text. The zig-zag pattern means taking an element that is introduced in the rheme in the first clause becomes the theme in the second clause. Rheme in the second clause becomes a theme in the third clause and so on. The new information in the second sentence is derived from the information in the previous clause. Multiple patterns introduce several different pieces of information, each of which is then picked up and made theme in subsequent clauses.

According to the analysis of text 1 , it was found zig-zag pattern and theme reiteration fold within the text. It can be seen as an example of zig-zag pattern in Table 1.

Zig-Zag pattern was employed by stating idea in theme 1 (The problem in this project) that is explained by rheme 1 (is about inventory). Then rheme 1 was taking up to the idea in the theme 2 (For exporters, it). The referent "it" refers to inventory and explained by rheme 2 (is certainly very difficult to know the inventory of goods that must be prepared every month).

Table 1. The example of zig-zag pattern

\begin{tabular}{|c|c|c|}
\hline & Theme & Rheme \\
\hline Clause 1 & $\begin{array}{l}\text { The problem in this } \\
\text { project }\end{array}$ & is about inventory \\
\hline Clause 2 & For exporters, it & $\begin{array}{l}\text { is certainly very difficult to know the } \\
\text { inventory of goods that must be prepared } \\
\text { every month }\end{array}$ \\
\hline
\end{tabular}

Table 2.The example of theme reiteration

\begin{tabular}{lll}
\hline & Theme & Rheme \\
\hline Clause 36 & Water & is one of the main resource in daily life \\
\hline Clause 37 & $\begin{array}{l}\text { Water become one of } \\
\text { the elements }\end{array}$ & $\begin{array}{l}\text { that can meet our daily needs and guarantee } \\
\text { the continuity of life }\end{array}$ \\
\hline
\end{tabular}


Theme reiteration pattern was employed by explaining theme 36 (Water) in rheme 36 (is one of the main resource in daily life). Then the idea in theme 36 was taken up into theme 37
(Water become one of the elements) and it was explained by rheme 37 (that can meet our daily needs and guarantee the continuity of life).

Table 3. The example of multiple rheme

\begin{tabular}{lll}
\hline & Theme & Rheme \\
\hline Clause 15 & In this study & $\begin{array}{l}\text { a comparison of the Data Encryption } \\
\text { Standard (DES) and Advanced Encryption } \\
\text { Standard (AES) algorithms will be } \\
\text { implemented in the encryption module } \\
\text { encrypted and sent to the server }\end{array}$ \\
Clause 16 & Data from the sensor & \\
\hline clause 17 & $\begin{array}{l}\text { The time and power will be compared with AES } \\
\text { consumption by DES). }\end{array}$ \\
\hline
\end{tabular}

Multiple rheme was also employed by the writer as shown in theme 15 (In this study) that was explained by rheme 15 (a comparison of the Data Encryption Standard (DES) and Advanced Encryption Standard (AES) algorithms will be implemented in the encryption module). Then the idea of rheme 15 was taken up to theme 16 (Data from the sensor) and theme 17 (The time and power consumption by DES).

The above examination answers the third research question dealing with the quality of micro-level coherence in the text. It involves the sentence level analysis that reveals the thematic pattern of each text.Thematic progression represents the writer's strategies to linkthe themes and rhemes in a clause to all of surrounding clauses in a text (Hawes, 2015). According to the analysis, three types of the thematic pattern were found in the texts. It confirms Priangan et al. (2019)and Rahmawati and Kurniawan's (2015) study that all types of the thematic pattern were found in students' text. However, the writers of the text seem are not well organized in arranging the sentences. One text might consist of more than one type of thematic pattern. Even though, the text is still readable and could be understood by the readers. This finding verifies Liyana's (2014) study that non-native students can achieve coherency in their text but there are some parts that are less coherent.

On the other hand, the macrolevelcoherence comprises the analysis of readers' engangement with the text. It should be related to the context and topic (Thornbury, 2005). Coherence is achieved not by using superficial markers as linguistic, grammatical devices, etc., but bypsychological, cognitive, pragmatic devices, etc. (Wang, 2014).The result of analysis showed that ten final project abstracts have comprehensible topic. For instance, the first final project abstract generally discusses the same topic in the whole text. It is talking about "Using Linear regresssion to predict the sales". The macro-level was coherence also achieved through the analysis of generic structure of the text. Since the object of the study is the abstract of final project, it shouldcontain of overview of the study, aim of the study, reason for the study, methodology used in the study, and findings of the study (Paltridge \& Starfield, 2007).

Unfortunately, none of the text has fulfilled the form proposed by the experts. For instance, final project abstract 1 consists of overview of the study, reason for the study, methodology used in the study, and findings of the study. There is no aim of the study that should be placed after overview of the study. One type of text can also 
be identified through language features. As the text in this study is final project abstract that regards to research activities that have been completed. So that it should use simple past tense. According to the analysis of text 1 , it was found that the writer used simple present tense in writing the text. It can be seen from clause 1 "The problem in this project is about inventor". Tobe indicated the use of simple present tense. The use of simple future tense also occured in text 1 . Clause 3 showed the existence of simple future "If one provides goods inventory, it will hamper the sale of goods". Modal auxiliary willindicated that the sentence used simple future tense.

The result of analysis acknowledges the fourth research question regarding the quality of macro-level coherence. The text should be on track to fulfill the analysis of macro-level coherence. As the text is in the form of the final project abstract, it should consist of an overview of the study; the aim of the study; the reason for the study; the methodology used in the study; the Findings of the study (Paltridge \& Starfield, 2007). Unfortunately, the result of the analysis showed that none of the text was employed a good generic structure. Some parts were not used while others were misplaced. The specific genre can be identified by analyzing its language features. In this study, the text is in the form of final project abstract that indicated the use of simple past tense. The result of the analysis showed that the tenses used in ten final project abstracts are simple present tense and simple future tense.

According to the analysis result of micro and macro-level coherence, all text does not satisfy the requirement as good final project abstract. However, the text can be said coherent regarding the existence of cohesive devices that help in achieving coherency among the sentence. The present results show the existence of two types of cohesion. In terms of grammatical cohesion, all types of grammatical cohesion were used in writing ten final project abstracts. Those are reference, ellipsis, substitution, and conjunction. Reference and conjunction have occurred most of the time while ellipsis and substitution occurred in limited portions. In terms of lexical cohesion, only four types of it that were used in writing ten final project abstracts. Those are repetition, synonymy, hyponymy, and meronymy. While collocation was not found in ten final project abstracts. Repetition still becomes the preferred choice by non-native writers since the writers have helped the readers to follow the meaning of the text from the beginning to the end of the paragraph. They also used it to avoid monotonous writing text by using cohesive devices.

\section{Open-ended Questionnaire}

Open-ended questionnaires were used to reveal the reason why the students use these kinds of cohesion and coherence in their final project abstract. Eight questions were proposed to the writers. In answering the first question dealing with difficulties in creating the final project abstract, there were five main different arguments. Those were about summarizing research and drawing a conclusion, using correct grammatical in delivering the idea, creating sentences, choosing suitable vocabulary, and translating Bahasa Indonesia into English. In answering the second question associated with the writers' knowledge about the generic structure of the final project abstract, nine writers are arguing that they knew about it while one argued did not know. In answering the third question about the writers' difficulty in grammar, there are three main different arguments. It was about using grammatical rules for formal language, using appropriate tense, and using article, word order, and prepositions. One writer argued that there was no difficulty in grammatical. In answering the fourth question concerning the writers' difficulty in lexical choices/vocabularies, there were two main different arguments. It was about choosing a special term for IT and choosing appropriate words for writing the final project.

In answering the fifth question regarding how the writers relate the idea among the sentences, there were eight different arguments. It was about translating each word and choosing which one was appropriate research, 
understanding the concept of the main sentence and supporting sentence, using Google Translate, explaining the main idea with supporting sentences, repeating mention the subject in following sentences, using conjunction, taking inspiration on news, using his knowledge. In answering the sixth question that deals with using a translation machine or application, it is found that there were two kinds of applications used. Those were Google Translate and Grammarly.

In answering the seventh question about having academic writing for the writing final project, there were four different arguments. Six people agreed that it was helpful. One argued that it was not suitable with the writing format from the faculty. The other explained it was helpful but the time was limited. One argued it should be reflected in the curriculum and students' needs. The last one stated that he didn't know about this lecture. In answering the eighth question dealing with students' expectations for having an English lecture, there are eight different arguments. Two people expected to have more credits for English lectures. Two people argued that English lecturers should be creative in delivering the materials. Three people argued that English lecturers should be full of conversation and focus on basic skills such as listening speaking, reading, and writing. The lecture should contain about grammar lesson because he thought it was the most difficult part in learning English for writing the final project. The respondent expected that there would be English lectures in each semester so the students can learn from basic. In answering the eighth question, the respondent explained that the lecture should introduce what kind of verbs in a formal or informal situation.

The result of open-ended questionnaire leads to the discussion of the fifth research question. It is questioning why the writers used these kinds of cohesion and coherence in their final project abstract. The way the writer answered the open-ended questionnaires shows that some of them admitted that they experienced difficulties in writing the final project abstract. In general, it deals with summarizing research, using correct grammatical in delivering the idea, creating sentences, choosing suitable vocabulary, and language translation. Regarding cohesion that consists of grammatical and lexical cohesion, the writers stated they still have tough. However, the result of the analysis showed that they can apply cohesive devices in their writing but some of them were in limited occurrence. Even though the writers explained their difficulties in choosing the special term for IT and appropriate words for writing the final project abstract, they were able to use synonymy, meronymy, hyponymy, and repetition.

Coherence brings sense to the readers about the text while it is not easy to be achieved. The writers acknowledged their thought especially in relating the ideas among the sentences. The result of the analysis also showed that in micro-level coherence, the text seems not well organized. One text might consist of more than one thematic development. It is also important for the writer to have a comprehension of the generic structure of the final project abstract and its language features to achieve macro-level coherence. Even though they argued that they 
have already known about it, the result of the analysis showed none of the final project abstracts fulfill the requirement of a good one as the expert suggested. This confirms the findings of Lutfiyah et al. (2015) who emphasized that in writing the abstract, the student's result is not well organized. The writer also declared in using translation applications to ease them in writing. Two kinds of applications were used. Those were Google Translate and Grammarly. The institution has provided lectures to help the students for increasing their writing skills because the students should submit the final project in English as one of their graduation requirements. Some students argued it is helpful but the time was limited. They expected to have more credits for English lectures and learn more from the basic skill in the interactive learning activity.

\section{Writing Abstract}

Abstract plays a crucial part in research because it summarizes the whole process to ease the reader getting the information in a short time (Paltridge \& Starfield, 2007).The last discussion was about the sixth research question that discussed the way to write a good final project abstract with correct cohesion and coherence. Some experts have proposed the theory on how to create proper abstracts in acknowledging certain genres to meet the readers' expectations.In his book, Paltridge and Starfield (2007) explained that abstract also has a generic structure that mainly discusses five main parts. Those are an overview of the study, the aim of the study, reasons for the study, methodology used in the study, and findings of the study. But it is not always the case. The generic structure of the abstract can be adjusted with the researcher's need. Following the institution guideline can be one of consideration in creating abstract.Abstract also has language features using verb tenses depending on what kind of research is. Paltridge and Starfield (2007) categorized it into two. The first is a summary of the thesis. It uses present simple in creating the abstract. The second is the report of the research. It uses past simple and present perfect. In writing the abstract, it is better to follow the guideline from the institution or refers to the book that discusses it.

\section{CONCLUSIONS}

The important finding of the study shows that the non-English department undergraduate students still have difficulties in creating good final project abstracts. However, they can use cohesive devices in their text to achieve coherency. In relating the ideas among the sentences, it seems not well-organized since in one text it might consist of more than one thematic development. The topic of each text is clear enough. The text can be said readable even though it is not in harmonious ways as good final project abstract.The intention for language learnerespecially non-English departments is that they need to know the concept of cohesion and coherence in creating text to avoid creating unorganized text. The present study can be used as a reference when the students want to create a text so that they do not make the same mistakes. The result of this study is also addressed to English lecturers. They should include academic writing in their classespecially the lesson about the texture or the elements of a text that consist of cohesive and coherent devices. These aspects of English are the crucial things in making meaning in the text (Jing, 2014). Study from Tahsildara and Yusoff (2018) showed that teaching of academic text has significant impact on student's written production. The last is for further researches or studies. This study focuses on the final project abstract written by Informatics Engineering students of Soegijapranata Catholic University. Therefore, it can be used as a reference for further researchers to study the quality of written texts produced by non-English department students in other universities from the different aspects of language.

\section{REFERENCES}

Adiantika, H. N. (2015). Cohesive devices in EFL students' expository writing. Journal of English Education, 4(1), 94-102.

Afrianto. (2017). Grammatical cohesion in students' writing: A caseatUniversitasTeknorat Indonesia. Leksema Jurnal BahasadanSastra, 2(2). 
Alzankawi, M. (2017).Kuwaiti undergraduate problems with cohesion in EFL writing. International Journal of Education, Learning and Development, 5(4), 55-65.

Ampa, A.T.\&Basri, M. (2019).Lexical and grammatical cohesions in the students' essay writing as the English productive skills.International Conference Computer Science and Engineering.

Eggins, S. (2004). An Introduction to Systemic Functional Linguistics. Continuum.

Fitriati, S.W. \&Fadhila Y. (2017).Examining text coherence in graduate students of English argumentative writing: Case study. Arab World English Journal, 8 (3), 251-264.

Halliday, M. A. K., \&Matthiessen, C. M. I. M. (2014).An introduction to functional grammar (4th ed.). Arnold.

Hartono, R., \& Purwanto, B. (2017). English Text Types: Theory, Practice, and Teaching Approach. Fastindo.

Hawes, T. (2015).Thematic progression in the writing of students and professionals. $A n$ International Journal of General and Applied Linguistics, 2, 93-100.

Heni, A. N., Syarif, H., \&Marlina, L. (2018).Lexical cohesive devices in narrative and exposition texts.E-Journal of English Language and Literature, 7(4). http://ejournal.unp.ac.id/index.php/jell

Jing, W. (2014). Theme and thematic progression in english learner: A literature review. Colombian Applied Linguistics Journal, 16(1), 67-80.

Karadeniz, A. (2017).Cohesion and coherence in written texts of students of faculty of education.Journal of Education and Training Studies, 5(2).

Kilic, M., Genc, B., \&Bada, E. (2016).Topical structure in argumentative essays of EFL learners and implications for writing classes.Journal of Language and Linguitic Studies, 12(2), 107-116.

Liyana, C. I. (2014). Cohesion and coherence in education students' thesis.Journal of Language Education and Humanities, 1(2), 281- 296.
Luthfiyah, Alek, \&Fahriany.(2015).An investigation in cohesion and rethorical moves in thesis abstracts. Indonesian Journal of English Education, 2(2), 145-159.

Malah, Z. (2015). Lexical cohesion in academic discourse: Exploring applied linguistics research articles abstracts. Research Journal of English Language and Literature (RJELAL)A Peer Reviewed (Refereed) International Journal. 3(4).

Masadeh, T. S. (2019). Cohesion and coherence in the writings of saudi undergraduates majoring in English.Journal of Social Sciences and Humanities, 5(3). 200-208.

Nilopa, L. M., Miftah, Z. M., \&Sugianto, A. (2017). Cohesive devices (CDS) inexpository essay written by Indonesian students of English as aforeign language (EFL). Journal of English Education, 6(2).

Nugraheni, R. (2015). Cohesive devices in learners' writing. LLT Journal: A Journal on Language and Language Teaching, 18(1).

Paltridge, B. \& Starfield, S. (2007). Thesis and Dissertation Writing in a Second Language. Routledge.

Priangan, A., Saleh, M.,\&Rukmini, D.(2019). Cohesion and coherence in undergraduate students' argumentative essays. English Education Journal, 10 (1), 28 - 36.

Rahmawati, R. V., \&Kurniawan, E. (2015). Thematic progression analysis in Indonesian EFL students' thesis abstracts. Indonesian EFL Journal, 1(1). 89-96.

Sadighi, F., \&Heydari, P. (2012). Cohesion analysis of L2 writing: The case of Iranian undergraduate EFL learners. Mediterranean Journal of Social Sciences, 3(2).

Shakeh, N. A. (2016). Thematic progression in the rhetorical sections of an online Iraqi English newspaper. International journal of Foreign Language Teaching and Research,4(5),59-68.

Suwandi. (2016). Coherence and cohesion: An analysis of the final project abstracts of the undergraduate students of PGRI Semarang. Indonesian Journal of Applied Linguistics, 5(2), 253-26. 
Tahsildara, M. N. \&Yusoff, Z. S. (2018).Impact of teaching cohesive devices on L2 students' language accuracy in written production. Academy Journal of Educational Sciences, 2(1), 16-28.

Tajeddin, Z. \&Rahimi, A. (2017).A conversation analysis of ellipsis and substitution in global business english textbooks.International Journal of Society, Culture, \& Language IJSCL, 5(1), 1-14.
Thornbury, S. (2005). Beyond the sentence: Introducing discourse analysis. Macmillan Publishers Limited

Wang, Y., \&Guo, M. (2014).A short analysis of discourse coherence. Journal of Language Teaching and Research, 5, 460-465.

Weigle, Sara Cushing. (2002). Assessing Writing. United Kingdom: CambridgeUniversity Press. 